Arq. Bras. Med. Vet. Zootec., v.56, n.2, p.267-269, 2004

\title{
Comunicação
}

[Communication]

\section{Efeito da suplementação de vitamina A sobre a incidência de mastite em vacas da raça Holandesa}

\author{
[Effect of vitamin A on incidence of mastitis in Holstein cows]
}

\author{
J.J. Paschoal, M.A. Zanetti
}

Faculdade de Zootecnia e Engenharia de Alimentos - USP

Alameda dos Corimbatás, 855 - Cidade Jardim

13632-466 - Pirassununga, SP

Estudos com vitamina A têm comprovado sua influência sobre a manutenção da integridade funcional do tecido epitelial mamário e o seu envolvimento com a resposta imune celular (Krishnan et al., 1974).

Rapp e Richard (1961), ao utilizarem culturas in vitro do canal de tetos bovinos, observaram influência da vitamina A sobre a secreção de queratina e verificaram haver uma barreira física protetora contra a entrada de microorganismos patogênicos. Chew et al. (1982), ao trabalharem com 45 vacas em lactação, com o objetivo de investigar a relação entre a concentração de vitamina no sangue e a incidência e severidade de infecção na glândula mamária, verificaram que as infecções mamárias mais severas ocorreram em animais com baixa concentração plasmática de vitamina A. Johnson e Chew (1984), em um experimento de longa duração, estudaram a relação entre concentração de vitamina A no sangue no pré-parto e incidência de mastite subclínica e concluíram que as vacas com mastite $(\mathrm{CCS}>50.000 \mathrm{cél} / \mathrm{ml})$ apresentaram menor concentração de vitamina A no sangue, durante a primeira, segunda e terceira semanas pós-parto. Dahlquist e Chew (1985) relataram que vacas suplementadas com vitamina A tiveram menor taxa de novas infecções no período pós-parto, quando comparadas com aquelas que não receberam suplementação. No experimento de Oldham et al. (1991), os autores dividiram as vacas em três tratamentos: 1suplementadas com 50.000UI vit.A/dia, 2suplementadas com 170.000 UI vit.A/dia e 3suplementadas com 50.000UI vit.A/dia $+300 \mathrm{mg}$ de B-caroteno/dia. Não houve diferença entre tratamentos quanto à concentração sérica de vitamina A. Freqüência de mastite clínica, porcentagem de novas infecções e contagem de células somáticas (CCS) no leite durante o período seco, ao parto e nas primeiras semanas de lactação, não foram influenciadas pelos tratamentos.

Este trabalho teve como objetivo avaliar o efeito da suplementação de vitamina A sobre a incidência de mastite em vacas da raça Holandesa.

Recebido para publicação em 7 de fevereiro de 2003 
Quarenta e duas vacas holandesas foram divididas em blocos, de acordo com a ordem de parição, e distribuídas em dois tratamentos: controle e suplementadas com 180.000UI vit.A/dia ${ }^{1}$. Todos os animais foram tratados com antibiótico intramamário específico para vacas secas $^{2}$, no momento da secagem. As doses diárias de vitamina A foram pesadas, acondicionadas em saquinhos de papel e colocadas diretamente na boca dos animais. A suplementação foi iniciada 30 dias antes da provável data de parição, prolongando-se até a data do parto.

As vacas secas receberam silagem de milho ( $22 \mathrm{~kg}$ na matéria original/vaca/dia), silagem de capim napier ( $5 \mathrm{~kg}$ na matéria original/vaca/dia) e concentrado formulado e misturado na própria fazenda ( $4 \mathrm{~kg}$ namatéria original/vaca/dia).

O exame de Tamis (Radostits, 1994) e as colheitas de leite para levantamento da CCS foram feitas, semanalmente, durante a ordenha da tarde, seguindo a rotina da propriedade.

Utilizou-se o delineamento em blocos ao acaso, de acordo com a ordem de parição dos animais. Os valores da CCS foram transformados em $\log _{\mathrm{e}}$ por não seguirem uma distribuição normal. Os dados foram analisados usando-se o programa Proc Mixed do SAS (User's..., 1982). Para análise dos resultados de mastite clínica determinaram-se os valores do qui-quadrado pelo programa GRAPHPAD INSTAT, aplicando-se o teste de Fisher.

Os resultados relacionados à freqüência de casos clínicos, observados até $12^{\mathrm{a}}$ semana de lactação, são apresentados na Tab. 1.

Tabela 1. Porcentagem de casos positivos por animal nas doze primeiras semanas de lactação, de acordo com os tratamentos

\begin{tabular}{lccc}
\hline & & \multicolumn{2}{c}{ Casos positivos } \\
\cline { 3 - 4 } Tratamento & $\begin{array}{c}\text { Número de } \\
\text { observações }\end{array}$ & $\mathrm{N}$ & $\%$ \\
\hline Vit. A & 252 & 11 & $4,36 \mathrm{a}$ \\
Controle & 230 & 26 & $11,30 \mathrm{~b}$ \\
\hline Valores seguidos por letras distintas na coluna diferem entre \\
si (P<0,05) \\
* Números de animais por tratamento $\times$ número de \\
diagnósticos realizados por animal.
\end{tabular}

\footnotetext{
${ }^{1}$ Roche Inc.
}

${ }^{2}$ Rilexine ${ }^{\circledR}$
Ambos os tratamentos apresentaram freqüência de casos clínicos inferior a $12 \%$, resultado bastante próximo daquele encontrado por Valle (2000), quando trabalhou com rebanhos leiteiros no Estado de Minas Gerais.

Em geral, a mastite é causada pela invasão do úbere por bactérias (Fonseca, Santos, 2000). Se elas não forem rapidamente destruídas, desencadeia-se uma resposta imune prolongada, com produção de substâncias responsáveis pelo aparecimento de sinais clínicos da doença, aumentando a severidade do caso (Suriyasathaporn et al., 2000).

O tratamento com vitamina A diminuiu significativamente $(\mathrm{P}<0,05)$ a freqüência de casos clínicos, diagnosticada pelo teste de Tamis.

Estes resultados são semelhantes aos obtidos por Chew et al. (1982). Esses autores concluíram que a deficiência de vitamina A aumentou a incidência de casos positivos de mastite e atribuíram o estabelecimento da infecção ao decréscimo na secreção de queratina e à diminuição na transferência de imunoglobulinas e de leucócitos para a glândula mamária. Dahlquist e Chew (1985) relataram que vacas suplementadas no pré-parto com $180000 \mathrm{UI}$ de vitamina A diárias obtiveram menor taxa de novas infecções no período pós-parto, quando comparadas com aquelas que não receberam suplementação.

Com relação à CCS no leite (Tab. 2), os valores foram semelhantes nos dois grupos $(\mathrm{P}>0,05) \mathrm{e}$ maiores que $200.000 \mathrm{cel} / \mathrm{ml}$, valor indicador de mastite subclínica (Fonseca, Santos, 2000).

É provável que os animais de ambos os tratamentos tenham tido contato com os microrganismos causadores da doença e tenham desencadeado uma resposta imunológica imediata, caracterizada pelo aumento na CCS. A manutenção funcional das células de defesa e do tecido epitelial secretor, provavelmente explica a menor freqüência de casos clínicos nos animais tratados com vit. A. 
Tabela 2. Média e EPM da $\operatorname{CCS} \times 10^{3}$ e CCS $\log _{e}$, até a $12^{\mathrm{a}}$ semana de lactação, de acordo com os tratamentos

\begin{tabular}{lcccc}
\hline & Suplementado com vitamina A & & Controle & \\
\hline $\mathrm{CCS}, \log _{\mathrm{e}}$ & $5,8805 \pm 0,1990$ & NS & $5,6353 \pm 0,1990$ & NS \\
$\mathrm{CCS} \times 10^{3} \mathrm{cel} / \mathrm{ml}$ & $358 \pm 1,22$ & NS & $280 \pm 1,22$ & NS \\
\hline
\end{tabular}

CCS: contagem de células somáticas. EPM: Erro padrão da média.

Diferenças entre tratamentos não significativas (NS).

Palavras-chave: bovino leiteiro, CCS, pré-parto, qualidade do leite

\begin{abstract}
This experiment was designed to evaluate the influence of prepartum vitamin A supplementation on incidence of mastitis in Holstein cows. Forty two cows were randomly distributed into blocks according to the parity and divided in two treatments: control and supplemented with 180,000IU vit.A/day. The supplementation started 30 days before probable parturition date up to parturition. The Tamis test was performed weekly for clinical mastitis detection, and milk samples were collected for somatic cell counts. Vitamin A treatment decreased the incidence of clinical mastitis $(P<0.05)$, however no effect on milk somatic cell count was observed.
\end{abstract}

Keywords: dairy cattle, milk quality, prepartum, SCC

\section{REFERÊNCIAS BIBLIOGRÁFICAS}

CHEW, B.P.; HOLLEN, L.L.; HILLERS, J.K. et al. Relationship between vitamin A and BCarotene in blood plasma and milk and mastitis in Holsteins. J. Dairy Sci., v.65, p.2111-2118, 1982.

DAHLQUIST, S.P; CHEW, B.P. Effects of vitamin $\mathrm{A}$ and $\mathrm{B}$-carotene on mastitis in dairy cows during the early dry period. J. Dairy Sci., v.68 (Suppl.1), p.191, 1985. (Abst.).

FONSECA, L.F.L; SANTOS, M.V. Qualidade do leite e controle de mastite. 1.ed. São Paulo: Lemos Editorial, 2000. 175p.

JOHNSTON, L.A.; CHEW, B.P. Peripartum changes of plasma and milk vitamin $\mathrm{A}$ and $\mathrm{B}$ Carotene among dairy cows with or without mastitis. J. Dairy Sci., v.67, p.1832-1840, 1984.

KRISHNAN, S.; BHUYAN, U.N.; TALWAR, G.P. et al. Effects of vitamin $A$ and protein calorie undernutrition on immune responses. Immunology, v.27, p.383, 1974.

OLDHAN, E.R.; EBERHART, R.J.; MULLER, L.D. Effect of supplemental vitamin A or B-
Carotene during the dry period and early lactation on udder health. J. Dairy Sci., v.74, p.3775, 1991.

RADOSTITS, O.M.; BLOOD, D.C.; GAY, C.C. Veterinary medicine. London: Bailliere-Tindall, 1994. 173p.

RAPP, J.P.; RICHARD, C.G. The study of the effects of hormones and vitamin A on bovine teat canal in organ culture. Cornell Vet., v.61, p.1971, 1961.

USER'S guide: statistics. Version 5. Cary, NC : SAS Institute, 1982.

SURIYASATHAPORN, W.; SCHUKKEN, Y.H.; NIELEN, M. et al. Low somatic cell count: a risk factor for subsequent clinical mastitis in dairy herds. J. Dairy Sci., v.83, p.1248-1255, 2000.

VALLE, C.R. Influência da suplementação de vitamina $E$ nos periodos pré e pós parto na ocorrência de mastite clínica. 2000. $76 \mathrm{f}$. Dissertação (Mestrado) - Faculdade de Zootecnia e Engenharia de Alimentos, Universidade de São Paulo, Pirassununga, SP. 